\title{
Correction to: On the feasibility of studying the exospheres of Earth-like exoplanets by Lyman- $\alpha$ monitoring
}

\section{Detectability constraints for nearby $M$ stars}

\author{
Ana I. Gomez de Castro $^{1} \cdot$ Leire Beitia-Antero $^{1} \cdot$ Sabina Ustamujic $^{1}$ \\ Published online: 16 April 2019 \\ (C) Springer Nature B.V. 2019
}

\section{Correction to: Exp Astron \\ https://doi.org/10.1007/s10686-018-9574-5}

During typesetting the family name of the first author was incorrectly captured as Castro. The first author's given name is Ana and family name is Gomez de Castro.

Publisher's note Springer Nature remains neutral with regard to jurisdictional claims in published maps and institutional affiliations.

The online version of the original article can be found at https://doi.org/10.1007/s10686-018-9574-5

Ana I. Gomez de Castro aig@ucm.es

1 AEGORA Research Group, Universidad Complutense de Madrid, Plaza de Ciencias 3, 28040 Madrid, Spain 